\title{
Evaluation of the prognostic relevance of the recommended minimum number of lymph nodes in colorectal cancer-a propensity score analysis
}

\author{
Michaela Ramser ${ }^{1,2} \cdot$ Leonard A. Lobbes $^{3} \cdot$ Rene Warschkow $^{4,5} \cdot$ Carsten T. Viehl $^{6}$ • Johannes C. Lauscher ${ }^{3}$. \\ Raoul A. Droeser ${ }^{1} \cdot$ Christoph Kettelhack $^{1} \cdot$ Markus Zuber $^{1,2} \cdot$ Benjamin Weixler $^{3}$ (i)
}

Accepted: 5 January 2021 / Published online: 16 January 2021

(C) The Author(s) 2021

\begin{abstract}
Purpose Nodal status in colorectal cancer (CRC) is an important prognostic factor, and adequate lymph node (LN) staging is crucial. Whether the number of resected and analysed LN has a direct impact on overall survival (OS), cancer-specific survival (CSS) and disease-free survival (DFS) is much discussed. Guidelines request a minimum number of $12 \mathrm{LN}$ to be analysed. Whether that threshold marks a prognostic relevant cut-off remains unknown.

Methods Patients operated for stage I-III CRC were identified from a prospectively maintained database. The impact of the number of analysed LN on OS, CSS and DFS was assessed using Cox regression and propensity score analysis.

Results Of the 687 patients, $81.8 \%$ had $\geq 12 \mathrm{LN}$ resected and analysed. Median LN yield was 17.0 (IQR 13.0-23.0). Resection and analysis of $\geq 12 \mathrm{LN}$ was associated with improved OS (HR $=0.73,95 \% \mathrm{CI}: 0.56-0.95, p=0.033$ ), CSS (HR $0.52,95 \%$ CI: $0.31-0.85, p=0.030$ ) and DFS (HR $=0.73,95 \%$ CI: $0.57-0.95, p=0.030$ ) in multivariate Cox analysis. After adjusting for biasing factors with propensity score matching, resection of $\geq 12 \mathrm{LN}$ was significantly associated with improved $\mathrm{OS}$ ( $\mathrm{HR}=0.59$; 95\% CI: $0.43-0.81 ; p=0.002)$, CSS (HR $=0.34 ; 95 \%$ CI: $0.20-0.60 ; p<0.001)$ and DFS (HR $=0.55 ; 95 \%$ CI: $0.41-0.74$; $p<0.001$ ) compared to patients with $<12 \mathrm{LN}$.

Conclusion Eliminating biasing factors by a propensity score matching analysis underlines the prognostic importance of the number of analysed LN. The set threshold marks the minimum number of required LN but nevertheless represents a cut-off regarding outcome in stage I-III CRC. This analysis therefore highlights the significance and importance of adherence to surgical oncological standards.
\end{abstract}

Keywords Colorectal cancer $\cdot$ Lymph nodes $\cdot$ Overall survival $\cdot$ Disease-free survival $\cdot$ Propensity score analysis

Michaela Ramser and Leonard A. Lobbes contributed equally to this work.

Benjamin Weixler

benjamin.weixler@ charite.de

1 Clarunis Visceral Surgery Center, St. Clara Hospital \& University Hospital Basel, Basel, Switzerland

2 Department of Surgery, Kantonsspital Olten, Olten, Switzerland

3 Department of General, Visceral, and Vascular Surgery, Charité University Hospital, Campus Benjamin Franklin, Berlin, Germany

4 Department of Surgery, Kantonsspital St. Gallen, St. Gallen, Switzerland

5 Institute of Medical Biometry and Informatics, University of Heidelberg, Heidelberg, Germany

6 Department of Surgery, Spitalzentrum Biel/Bienne, Biel/ Bienne, Switzerland

\section{Introduction}

Colorectal cancer is still one of the most common malignancies and a leading cause of cancer-related death $[1,2]$. Surgical resection following oncologic principles including systematic lymphadenectomy is the treatment of choice. The resection and analysis of at least 12 lymph nodes (LN) is recommended by most national and international guidelines [3-7]. The lower limit of $12 \mathrm{LN}$ was set in 1990 by the World Congress of Gastroenterology [8]. However, this was rather a randomly selected numerical value, with no higher-level evidence available at the time. Whether that threshold marks a prognostic relevant cut-off remains unknown.

Over the years, the level of evidence improved, that in fact the number of $\mathrm{LN}$ was a relevant prognostic factor, preventing understaging by missed positive LN [9-12]. Since the 
presence of nodal metastases is still one of the most important prognostic factors in colorectal cancer, an adequate number of analysed LN is crucial $[9,13]$.

Given the nature of the problem, to our knowledge, no standard randomised trial addressing the validity of the set threshold of $12 \mathrm{LN}$ is available. Additionally, based on the existing evidence regarding the number of LN to be resected, conduction of a randomised study is no longer ethically justifiable. A propensity score matching analysis, which accounts for possible bias in non-randomised studies by eliminating the different distribution of observed variables between two groups, is one of the best ways to answer this question instead.

The aim of this study was to test whether the threshold of 12 resected and analysed LN actually marks a prognostic relevant cut-off level regarding cancer-specific outcome in patients operated for colorectal cancer, using propensity score matching.

\section{Methods}

Data for this retrospective study were extracted from the prospectively maintained cancer registry from three universityaffiliated institutions in Switzerland: the Department of Surgery at the University Hospital Basel, the Cantonal Hospital Olten and the Hospital Center Biel/Bienne. Between 1989 and 2013, a total of 1027 patients were treated for colorectal cancer at the three institutions. Patients with stage IV disease $(165 / 852,19.4 \%)$ were excluded from further analysis (Fig. 1). A total of 687 patients with stage I-III colorectal cancer were finally eligible for statistical analysis. For uniform histopathological tumour staging, all cases were
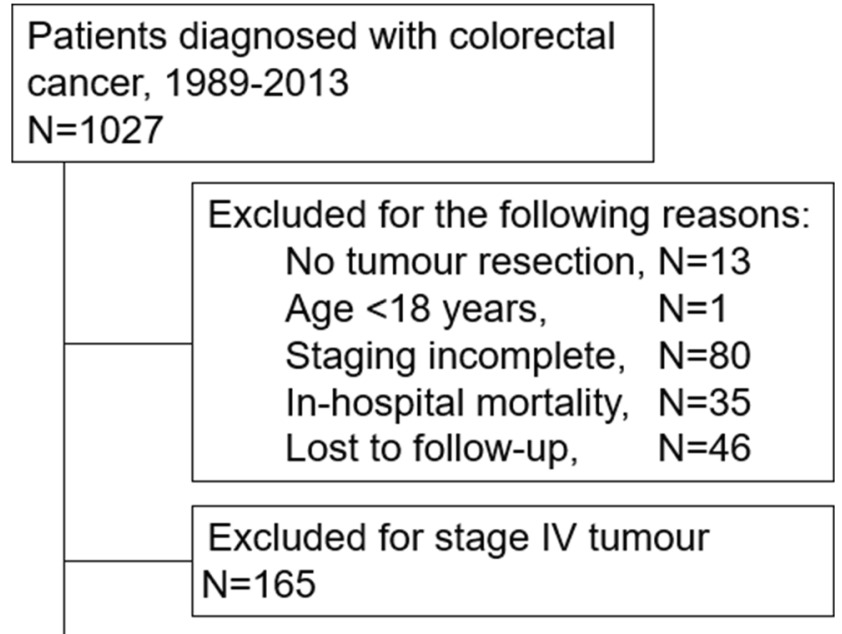

Final population with stage I-III colorectal cancer $\mathrm{N}=687$

Fig. 1 Flow chart of the selection process retrospectively reassessed and staged according to the 7 th TNM classification system at the time of follow-up data collection [14].

Data collection and analysis of the cancer registry was approved by the local ethical committee (EK 120/13 and clinicaltrials.gov identifier: NCT00826579). Approval of data collection was obtained prior to surgery (1989-2005), and a consent was obtained by letters of enquiry (20062013). Follow-up data and information on mortality were collected from the respective treating general practitioner, hospital records and the bureau of vital statistics.

(Neo)adjuvant radiation and/or chemotherapy was routinely offered to patients with a qualifying tumour stage or risk factors and in line with the respective recommendations and guidelines at the time.

\section{Statistical analyses}

Statistical analyses were performed using the R statistical software (www.r-project.org). A two-sided $p$ value $<0.05$ was considered statistically significant. Continuous data are expressed as means \pm standard deviation. For comparing proportions, chi-square statistics and, for comparing continuous variables, $t$ tests were used. For regression analysis, likelihood ratio tests were performed. After descriptive analysis, the bias concerning the number of resected and analysed LN ( $<12$ vs $\geq 12$ ) was assessed by logistic regression. Unadjusted and risk-adjusted Cox regression with robust sandwich variance estimators and stratification for the study centre were performed to assess the putative prognostic impact of the number of resected and analysed LN on overall (OS), cancer-specific (CSS) and disease-free survival (DFS). Multivariable Cox regression models were complemented by a backward variable selection based on the Akaike's information criterion. To optimally control for possible confounding differences in baseline characteristics, a bipartite weighting propensity score analysis was performed using the "matching" $\mathrm{R}$ package [15-19]. The baseline risk profiles of the matched patient characteristics were compared by conditional logistic regressions to assure that no major differences persisted. The prognostic value of $<12$ vs $\geq 12$ resected and analysed LN for OS, CSS and DFS was finally assessed in a stratified Cox regression analysis applying the subclasses and the weights obtained by the propensity score analysis.

The diagnostic accuracy of different cut-offs established by the numbers of resected and analysed LN was assessed by multimodel inference $[20,21]$ using resampling methods. The diagnostic accuracy was assessed in terms of the Akaike's information criterion (AIC) and the integrated area under the curve (iAUC) as described by Chambless and Diao [22]. For the AIC, multivariable Cox regression models with cut-offs between 5 and 20 for the number of resected and analysed LN with adjustment for colon/rectum, tumour stage, 
age and year of operation were fitted in resampled study data for OS, CSS and DFS survival. For each cut-off, 10,000 bootstrap samples were drawn, and Cox regression models were fitted for each survival measure in each of these samples. For each cut-off, the median of the AIC was estimated. For the iAUC, the study data were 10,000 times randomly divided into a training and a test data set. Multivariable Cox regression models with cut-offs between 5 and 20 for the number of resected and analysed LN with adjustment for colon/rectum, tumour stage, age and year of operation were fitted in the training data sets for OS, CSS and DFS. The fits obtained in the training data set were applied in the similar Cox models in the test data set. Based on the latter models, the iAUC was estimated using the R library "AUCsurv". Finally, the median of the iAUC was estimated for each cut-off.

\section{Results}

\section{Patient characteristics}

Demographic patient information and histopathological tumour details are shown in Table 1 . Overall, $22.9 \%$ of tumours were UICC stage I, $38.9 \%$ stage II and $38.3 \%$ stage III.

A majority of the patients were male $(56.8 \%)$. The larger proportion of tumours were localised in the colon, while $30.9 \%$ were rectal cancers. Overall, $91.6 \%$ of tumours were resected in an elective operation.

In $81.8 \%$ of all cases, $\geq 12 \mathrm{LN}$ were resected and analysed, while the median number was 17.0 (interquartile range (IQR) 13.0-23.0). The number of LN per patient differed significantly between patients with stage I, II and III colorectal cancer when analysed in a multivariable logistic regression model $(p<0.001)$ (Table 1).

The data on neoadjuvant and adjuvant therapy shows that overall, $12.1 \%$ of patients received radiation therapy and $33.0 \%$ chemotherapy (Table 1 ).

\section{Number of resected and analysed lymph nodes}

For further analysis, the population was divided into two groups with patients with less than 12 analysed LN $(<12)$ and 12 or more LN ( $\geq 12)$. Demographic information and tumour details of patients in the two groups are shown in Table 1. Over the years, the proportion of patients with more analysed LN increased. A difference in distribution between the two groups was also observed for tumour stage, tumour localisation, sex, the treating centre and indication for radiation therapy. On the other hand, age, grading and elective vs emergency operations were equally distributed between patients with fewer or more analysed LN. All of the above variables, expect for the tumour localisation and radiation therapy, remained significantly unequally distributed between the two groups in a multivariable logistic regression model (Table 1).

The 5-year survival rates for OS and DFS increased when more LN were analysed. Five-year OS rates for patients with $<12$ LN was $65.8 \%$ (95\% confidence interval (CI): 57.7 75.1 ) and $66.3 \%$ (95\% CI: $62.1-70.8$ ) for patients with $\geq 12$ LN. Five-year DFS for patients with $<12 \mathrm{LN}$ was $53.2 \%$ (95\% CI: 44.9-63.2) and 58.8\% (95\% CI: 54.5-63.5) for patients with $\geq 12 \mathrm{LN}$.

\section{Overall survival—uni- and multivariate analyses}

In univariate analysis, higher age at the time of operation, higher tumour stage and higher tumour grading were risk factors for decreased overall survival (OS), while localisation in the rectum and administration of chemo- and radiation therapy were factors for an improved OS. In multivariate analysis, higher age, higher tumour stage as well as needing radiation therapy were independent risk factors for a decreased OS, while localisation in the rectum and a higher number of resected and analysed $\mathrm{LN}$ ( $\geq 12 \mathrm{LN}$ ) were related to an improved OS (Table 2). The association between retrieval of $\geq$ $12 \mathrm{LN}$ and improved OS was confirmed in stepwise variable selection (HR $=0.73,95 \% \mathrm{CI}: 0.56-0.96, p=0.033)$.

\section{Cancer-specific survival-uni- and multivariate analyses}

In univariate analysis, higher age, higher tumour stage and emergency surgery were risk factors for decreased cancerspecific survival (CSS), while tumour localisation in the rectum was associated with an improved CSS. In multivariate analysis, higher age and higher tumour stage were independent risk factors for a decreased CSS, while a higher number of resected and analysed $\mathrm{LN}(\geq 12 \mathrm{LN}$ ) were related to an improved CSS (Table 2). The association between retrieval of $\geq 12 \mathrm{LN}$ and improved CSS was confirmed in stepwise variable selection $(\mathrm{HR}=0.52,95 \% \mathrm{CI}: 0.31-0.85, p=0.030)$.

\section{Disease-free survival—uni- and multivariate analyses}

In the univariate analysis, higher age, higher tumour stage and tumour grading were risk factors for a shorter disease-free survival (DFS), while tumour localisation in the rectum and chemotherapy improved DFS. In the multivariate analysis, higher age and higher tumour stage were independent risk factors for a decreased DFS, while $\geq 12$ resected and analysed LN was an independent factor improving DFS (Table 2). In the stepwise variable selection procedure, the retrieval of $\geq 12$ LN was selected as a significant predictor for improved DFS (HR $=0.73,95 \%$ CI: 0.57-0.95, $\mathrm{p}=0.030)$. 


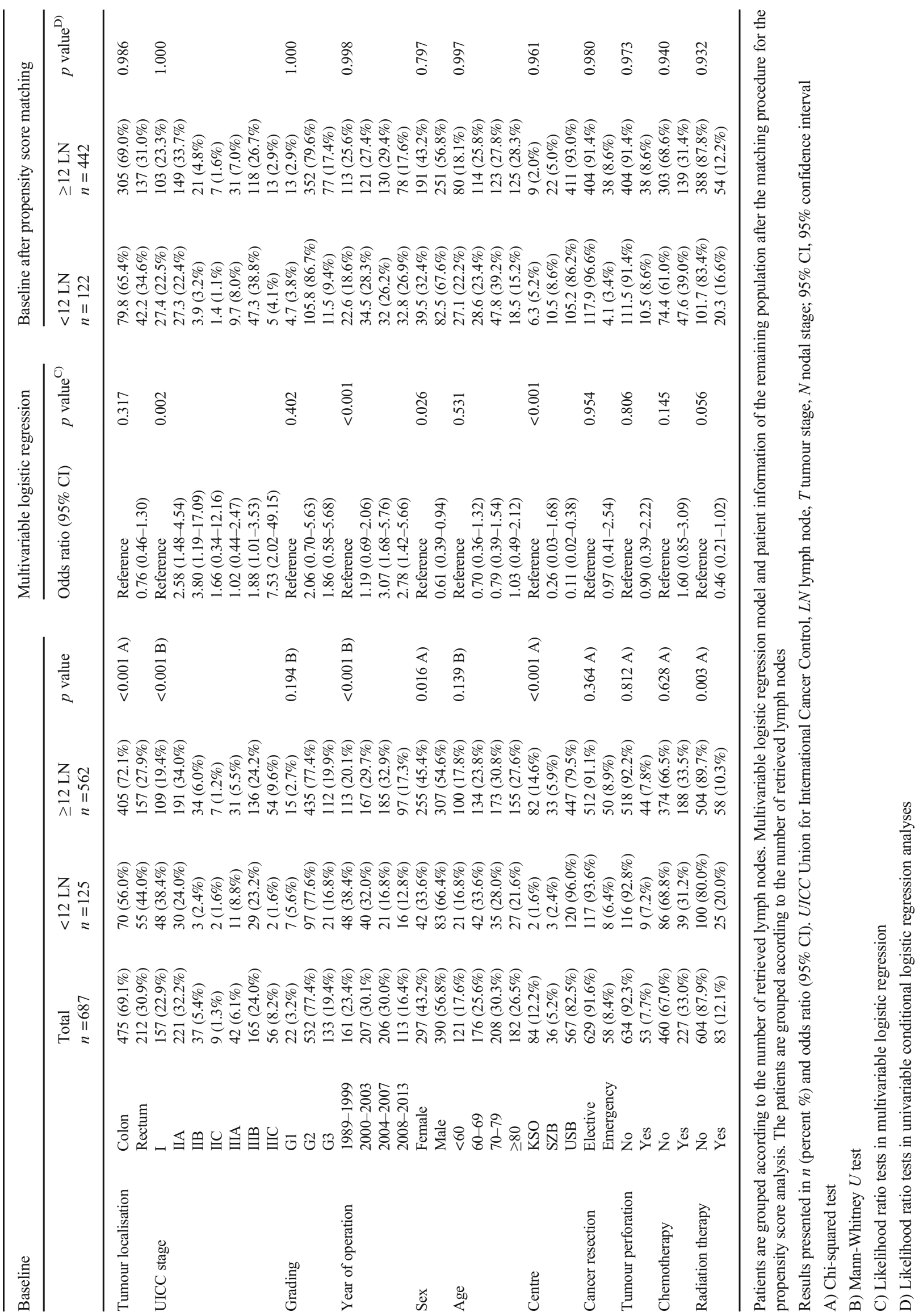




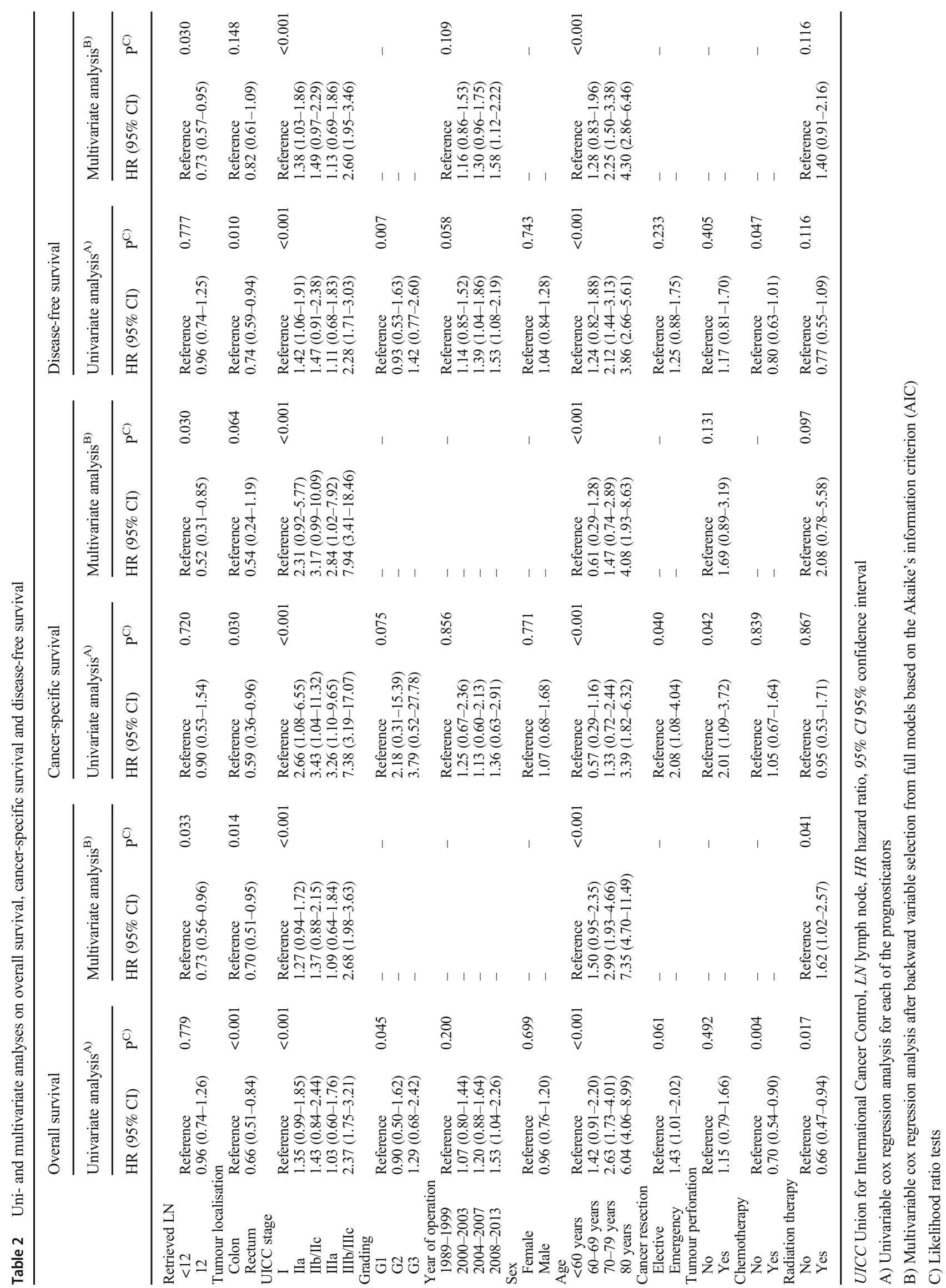




\section{Propensity score analysis}

Before the matching, the propensity score for patients with $<$ $12 \mathrm{LN}$ was $0.709 \pm 0.152$ compared to $0.808 \pm 0.124$ in patients with $\geq 12 \mathrm{LN}(p<0.001)$, thus indicating a strong and clinically relevant bias regarding the observed patient characteristics in the two groups (Table 1). After the matching procedure, the propensity score was the same in the two patient groups, $0.808 \pm 0.124$ for patients with $<12 \mathrm{LN}$ compared to $0.808 \pm 0.124$ for patients with $\geq 12 \mathrm{LN}(p=0.992)$, thus indicating no persisting bias regarding the observed patient characteristic in the two groups. Three patients of the $<12 \mathrm{LN}$ group and 120 patients of the $\geq 12 \mathrm{LN}$ group could not be matched, resulting in a population of 564 patients (Table 1).

\section{Survival analyses after the propensity score matching}

After the matching procedure for the propensity score analysis, 5-year OS for patients with $<12$ analysed LN was 53.3\% (95\% CI: 44.1-64.6) compared to $69.0 \%$ (95\% CI: 64.4-73.8) for patients with $\geq 12$ analysed LN (HR $=0.59,95 \%$ CI: $0.43-$ $0.81, p=0.002$ ) (Fig. 2a, b).

Five-year CSS after propensity score matching was $72.2 \%$ (95\% CI: 61.9-84.3) for patients with $<12 \mathrm{LN}$ compared to 89.4\% (95\% CI: 85.4-93.6) for patients with $\geq 12 \mathrm{LN}$ (HR = $0.34,95 \%$ CI: $0.20-0.60, p<0.001$ ) (Fig. $2 c, d$ ).

Five-year DFS after the matching procedure for the propensity score analysis for patients with $<12 \mathrm{LN}$ was $41.5 \%$ (95\% CI: 31.9-53.8), while it was 61.7\% (95\% CI: 56.8-67.0) for patients with $\geq 12 \mathrm{LN}$ (HR $=0.55,95 \%$ CI: $0.41-0.74$, $p<0.001$ ) (Fig. 2e, f).

\section{Multimodel inference for diagnostic accuracy of different cut-offs}

For OS and CSS, multimodel inference suggests more than 12 resected and analysed LN (Fig. 3). Low values for AIC and high values for iAUC indicate a better diagnostic accuracy. In terms of AIC, the statistically optimal cut-off was $14 \mathrm{LN}$ for OS (AIC of 812.6) and $13 \mathrm{LN}$ for CSS (median AIC of 811.6). For iAUC, the highest values were observed for 14 and $15 \mathrm{LN}$ alike (median iAUC of 0.796). For DFS, inconsistent results were obtained (data not shown).

\section{Discussion}

The recommendation to analyse at least $12 \mathrm{LN}$ in patients with colorectal cancer to avoid understaging has been set relatively arbitrary, and sound evidence for this threshold is missing. By using a propensity score analysis, the here presented study demonstrates a significant improvement in OS, CSS and
Fig. 2 Adjusted survival curves for overall survival $(\mathbf{a}, \mathbf{b})$, cancer-specific survival (c, d) and disease-free survival (e, f). (a) Comparing patients with $<12$ analysed LN and patients with $\geq 12$ LN on OS in all stage I-III patients. (b) After adjustment by propensity score matching, 564 patients remain for further analysis and the effect the number of retrieved $\mathrm{LN}$ on OS has markedly increased. (c) Comparing patients with $<12$ analysed LN and patients with $\geq 12$ LN on CSS in all stage I-III patients. (d) After adjustment by propensity score matching, 349 patients remained for further analysis and the effect the number of retrieved LN on DFS has markedly increased. (e) Comparison of patients with $<12$ patients and patients with $\geq 12$ analysed LN regarding DSF in stage I-III colorectal cancer patients. (f) After adjustment by propensity score matching, 564 patients remain for the analysis and the effect the number of retrieved LN on DFS has markedly increased

DFS if $\geq 12$ LN are resected and analysed, thus clearly supporting the threshold of a minimum of $12 \mathrm{LN}$. The applied propensity score analysis eliminates most of the biasing factors between the two patient groups mimicking a "retrospective randomisation" of the included patients. Given the nature of the problem, to our knowledge, a standard randomised trial addressing the validity of the set threshold of $12 \mathrm{LN}$ is not available, and the here used approach is probably the best way to answer this question.

Results from large series like the SEER database observed that only about $40 \%$ of patients had a sufficient number of LN examined [23, 24]. More recent results support the trend to more thorough resections and staging procedures. Numbers from a Swiss multicentre study, assessing results from operations between 2001 and 2005 , were also able to obtain good quality specimens with a median number of LN of 16 (range 9-24) [25]. These results correspond with the results presented here where $82 \%$ of the 687 patients had $\geq 12 \mathrm{LN}$ analysed (Table 1), and we also noted an increase in the LN yield over the years. Further, the chance for an adequate lymphadenectomy was increased in patients with a higher tumour stage and younger age. The fact that the number of resected and analysed LN significantly differed according to the year of operation is not surprising. The importance of the LN itself and the fact that not only positive $\mathrm{LN}$ but also the total number of LN was important had emerged only over time, and much of that awareness is attributable to several seminal publications at the time $[23,26]$.

However, we are not able to fully explain why the distribution of the number of resected LN is different between different stages of colorectal cancer. It might be that with early stage tumours, surgeons tend to be not as radical as with advanced stage disease, at least in the time period when the study was carried out. Another factor could be that smaller and less invasive tumours cause a less pronounced immune response what makes LN detection for pathologists more difficult. Importantly, around one-third of patients with stage I tumours 

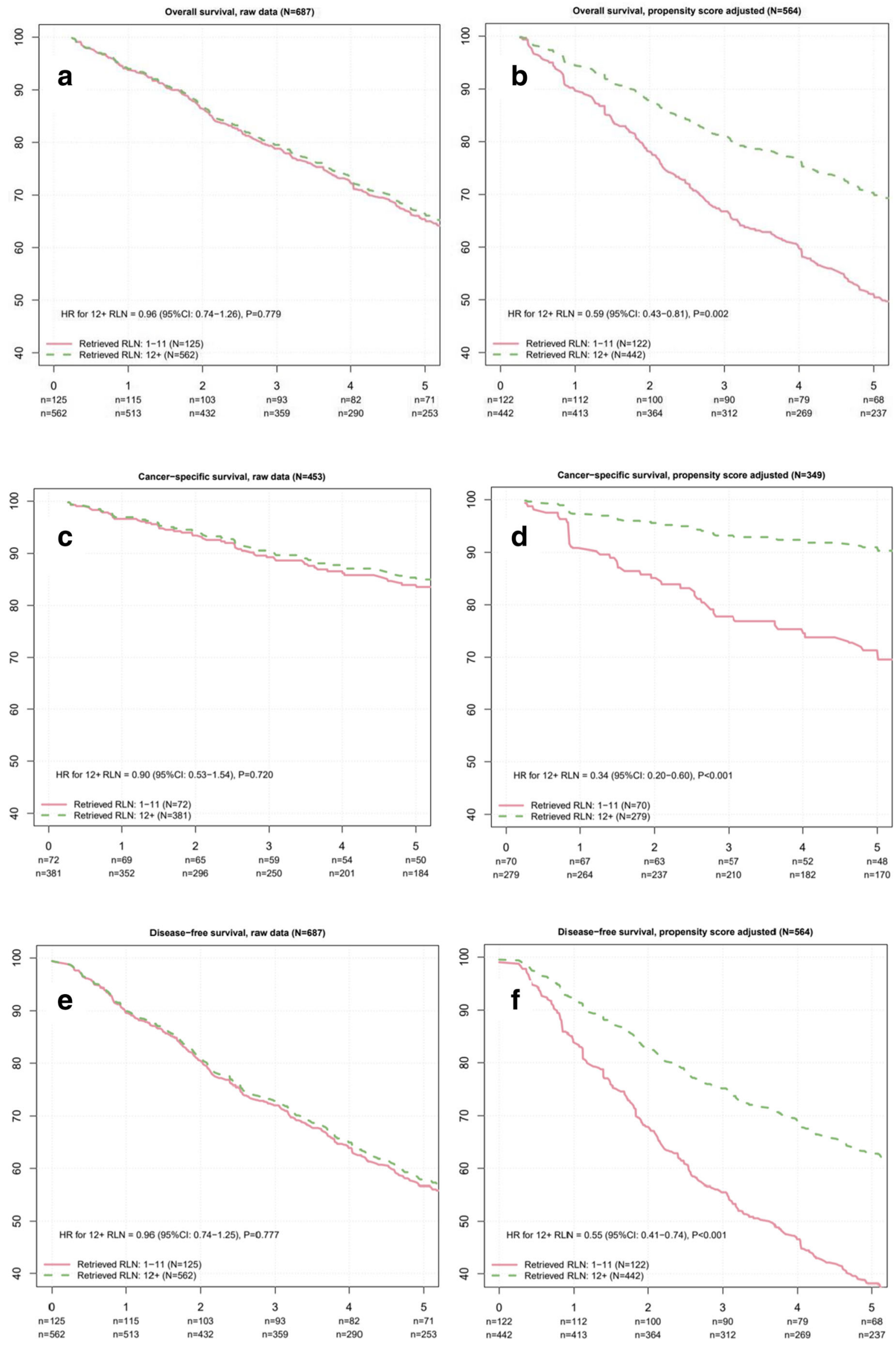
had $<12 \mathrm{LN}$ analysed but only about half of that proportion with stage II tumours. It is important to emphasise these results, as especially patients with a stage II tumour benefit from a proper staging and adequate adjuvant therapy if upstaged to stage III [27-30].

The number of analysed LN was considered an independent risk factor for OS, CSS and DFS in multivariate but not univariate Cox analyses (Table 2). Interestingly, only after eliminating biases between the two groups by a matching procedure for the propensity score analysis, the true impact of the number of resected and analysed LN on OS, CSS and
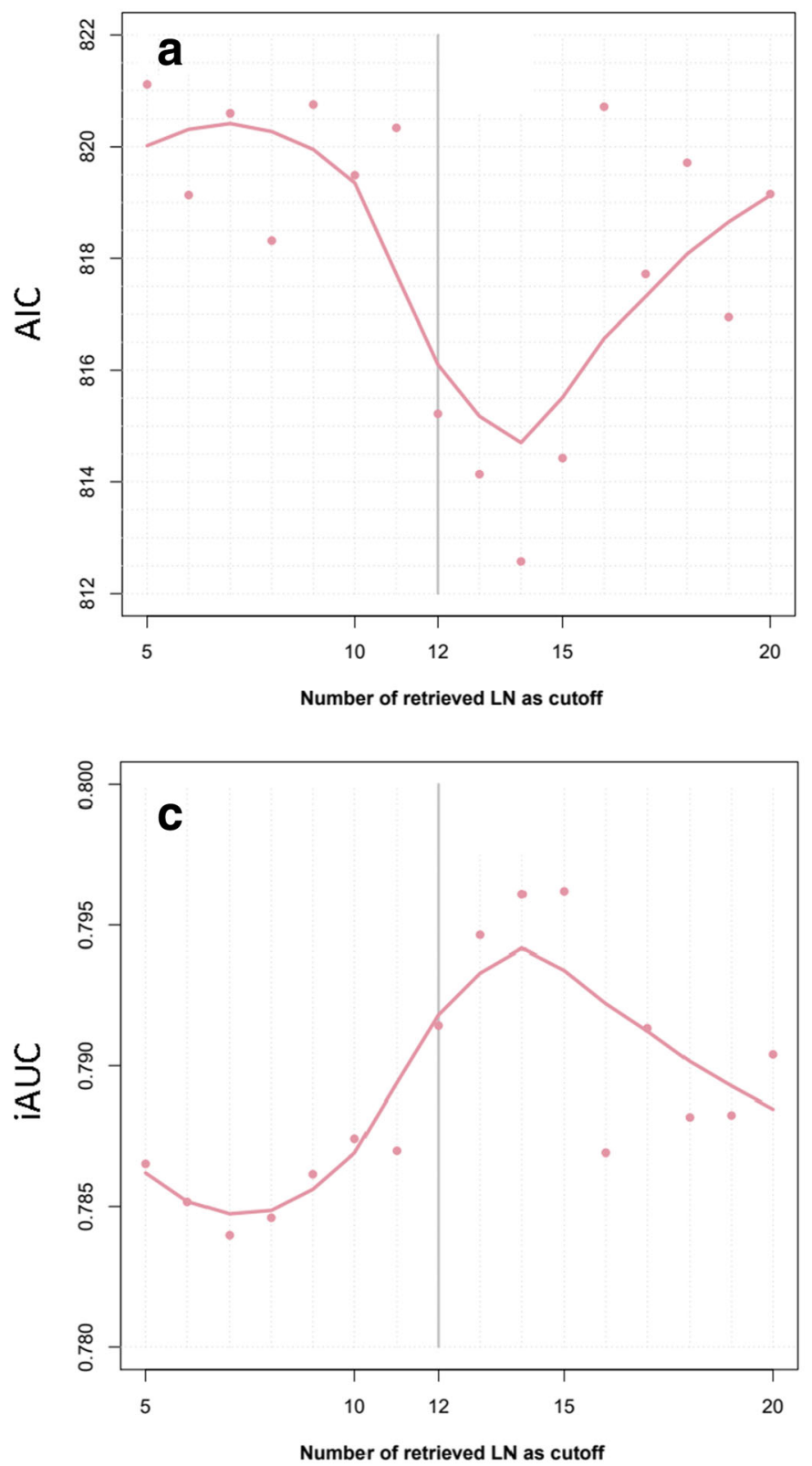

Fig. 3 Akaike's information criterion (AIC) for overall survival (panel a) and cancer specific (panel b) and the integrated area under the curve (iAUC) for overall survival (panel c) and cancer specific (panel d) in resampling analyses for 5 to 20 resected and analysed lymph nodes for
DFS was revealed (Fig. 2). Thus, underlining the importance of a thorough analysis and an equal distribution of confounding factors before a comparison between two groups of patients is attempted.

Understaging colorectal cancer by not analysing a sufficient amount of LN has a significant impact on patients' outcome as shown with this analysis. The risk of missing positive LN is significantly higher if $<12$ are analysed. The number of resected and analysed LN has therefore become an unofficial marker for the quality of surgery, a threshold that was clearly confirmed by this study. But
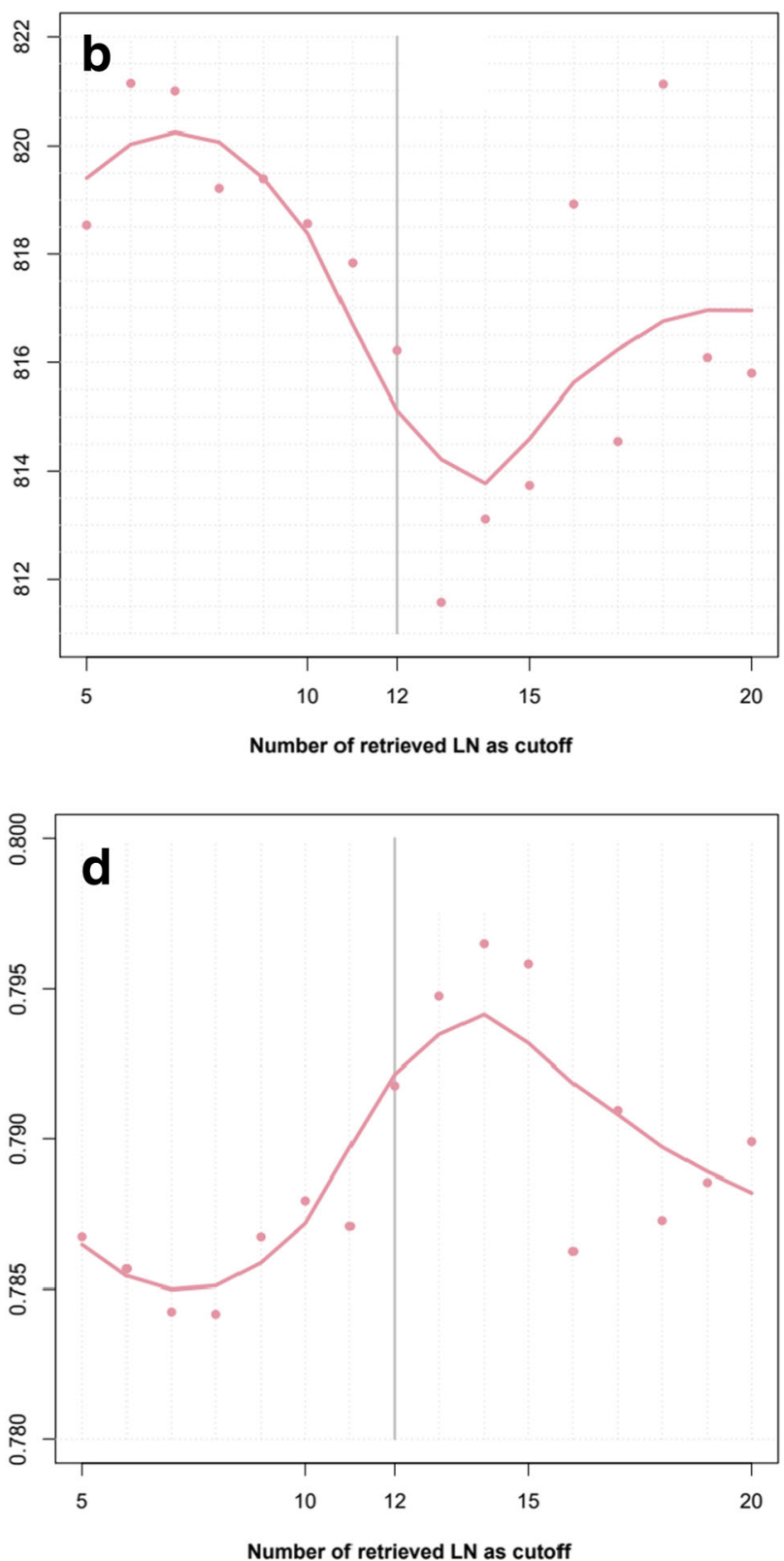

diagnostic accuracy in multimodel inference. Lower AIC and higher iAUC indicate higher diagnostic accuracy of the cut-offs. The dots represent the observed median values, and the lines are LOESS regression lines 
other factors influence the number of analysed LN as well: a dedicated team of pathologists is needed, and tumour-related factors like tumour size and stage as well as patient-related factors like age, the patients' immune system or the amount of fat that is present in the mesentery can make retrieval of LN more difficult [28, 31-34]. For that reason, different techniques to facilitate the pathologists' task to identify as many $\mathrm{LN}$ as possible were developed [35-40]. Further, sentinel LN mapping was demonstrated to improve identification of the first draining $\mathrm{LN}$ in the very hierarchical lymphatic draining system from the tumour. The sentinel LN has been shown to harbour tumour cells significantly more often than any other resected and analysed LN in a given specimen [41, 42].

The newest development in colon surgery on the other hand goes into a distinctly different direction: Not a more thorough analysis of a resected specimen is the highest goal but a more extensive resection including even the last $\mathrm{LN}$ in the draining hierarchy from a tumour $[43,44]$. CME could be associated with improved survival but on the contrary also with increased morbidity [45-47].

Whether a more in-depth analysis of a specimen resected according to standard oncologic techniques, respecting plains and the anatomy or whether a more extensive resection and a standard histopathologic analysis is the future remains to be seen.

We would like to acknowledge the limitations of our study. While patients were included in the database over a period of 25 years, the follow-up period was not longer than in comparable studies. Nevertheless, we were able to detect a significant difference in regard to OS, CSS and DFS. It is estimated that more than $80 \%$ of recurrence occurs in the first 2 years after treatment, and follow-up of more than 5 years is not recommended [48]. Additionally, more than $56 \%$ of the patients were $\geq$ 70 years old at the time of the operation, and oncological follow-up might have been adjusted to age, and general health or postoperative surveillance, as recently demonstrated by our group, was inadequately executed $[49,50]$.

In summary, according to our data, the cut-off level of 12 LN seems justified. All relevant oncologic outcome measures of OS, CSS and DFS of colorectal cancer patients are significantly improved if the required number of $\mathrm{LN}$ are included in the specimen and analysed. The difference becomes even more obvious if all biasing factors were eliminated with a propensity score matching analysis, thereby supporting the here used statistical method if a standard randomised trial addressing the validity of the set threshold is not available. If recommendations and guidelines should be adjusted in the future, the results of our simulation suggest that a minimum number of 14 or $15 \mathrm{LN}$ would yield the most significant prognostic impact (Fig. 3).

\section{Conclusion}

Eliminating all biasing factors by a propensity score matching analysis underlines the prognostic importance of and the number of analysed lymph nodes. The set threshold marks the minimum number of required LN but nevertheless represents a cut-off regarding outcome in stage I-III CRC. This analysis therefore highlights the significance and importance of adherence to surgical oncological standards and suggests an adaptation of the number of minimally required lymph nodes for future guidelines.

Funding Open Access funding enabled and organized by Projekt DEAL.

\section{Compliance with ethical standards}

Conflict of interest The authors declare that they have no conflict of interest.

Ethical approval Ethics approval has been obtained.

Consent to participate Consent to participate has been obtained.

Consent for publication Consent for publication has been given by all authors.

Open Access This article is licensed under a Creative Commons Attribution 4.0 International License, which permits use, sharing, adaptation, distribution and reproduction in any medium or format, as long as you give appropriate credit to the original author(s) and the source, provide a link to the Creative Commons licence, and indicate if changes were made. The images or other third party material in this article are included in the article's Creative Commons licence, unless indicated otherwise in a credit line to the material. If material is not included in the article's Creative Commons licence and your intended use is not permitted by statutory regulation or exceeds the permitted use, you will need to obtain permission directly from the copyright holder. To view a copy of this licence, visit http://creativecommons.org/licenses/by/4.0/.

\section{References}

1. Fischer J, Hellmich G, Jackisch T, Puffer E, Zimmer J, Bleyl D, Kittner T, Witzigmann H, Stelzner S (2015) Outcome for stage II and III rectal and colon cancer equally good after treatment improvement over three decades. Int J Color Dis 30(6):797-806

2. Siegel RL, Miller KD, Jemal A (2017) Colorectal cancer mortality rates in adults aged 20 to 54 years in the United States, 1970-2014. JAMA 318(6):572-574

3. UICC, I.U.A.C., International Union Against Cancer (2009) TNM classification of malignant tumours, 7th edn. Wiley-Blackwell, West-Sussex

4. Brierley JD, Gospodarowicz M., Wittekind C, eds. International Union Against Cancer (UICC). TNM Classification of Malignant Tumours, 8th edn. Oxford: Wiley Blackwell, 2017

5. Labianca R et al (2013) Early colon cancer: ESMO clinical practice guidelines for diagnosis, treatment and follow-up. Ann Oncol 24(Suppl 6):vi64-vi72 
6. Vogel JD, Eskicioglu C, Weiser MR, Feingold DL, Steele SR (2017) The American Society of Colon and Rectal Surgeons Clinical Practice Guidelines for the Treatment of Colon Cancer. Dis Colon Rectum 60(10):999-1017

7. Amin MB, Greene FL, Edge SB, Compton CC, Gershenwald JE, Brookland RK, Meyer L, Gress DM, Byrd DR, Winchester DP (2017) The eighth edition AJCC cancer staging manual: continuing to build a bridge from a population-based to a more "personalized" approach to cancer staging. CA Cancer J Clin 67(2):93-99

8. Fielding LP, Arsenault PA, Chapuis PH, Dent O, Gathright B, Hardcastle JD, Hermanek P, Jass JR, Newland RC (1991) Clinicopathological staging for colorectal cancer: an International Documentation System (IDS) and an International Comprehensive Anatomical Terminology (ICAT). J Gastroenterol Hepatol 6(4): 325-344

9. Swanson RS, Compton CC, Stewart AK, Bland KI (2003) The prognosis of T3N0 colon cancer is dependent on the number of lymph nodes examined. Ann Surg Oncol 10(1):65-71

10. Sarli L, Bader G, Iusco D, Salvemini C, Mauro DD, Mazzeo A, Regina G, Roncoroni L (2005) Number of lymph nodes examined and prognosis of TNM stage II colorectal cancer. Eur J Cancer 41(2):272-279

11. Chang GJ, Rodriguez-Bigas MA, Skibber JM, Moyer VA (2007) Lymph node evaluation and survival after curative resection of colon cancer: systematic review. J Natl Cancer Inst 99(6):433-441

12. Moore J, Hyman N, Callas P, Littenberg B (2010) Staging error does not explain the relationship between the number of lymph nodes in a colon cancer specimen and survival. Surgery 147(3): 358-365

13. Lykke J, Jess P, Roikjaer O (2015) Increased lymph node yield is associated with improved survival in rectal cancer irrespective of neoadjuvant treatment: results from a National Cohort Study. Dis Colon Rectum 58(9):823-830

14. Sobin LH, Gospodarowicz M., Wittekind C, eds. International Union Against Cancer (UICC), TNM Classification of Malignant Tumours, 7th edn. New York: Wiley, 2009

15. Joffe MM, Rosenbaum PR (1999) Invited commentary: propensity scores. Am J Epidemiol 150(4):327-333

16. Rosenbaum PR (1987) Model-Based Direct Adjustment. J Am Stat Assoc 82(398):387-394

17. Rosenbaum PR (1989) Optimal matching for observational studies. J Am Stat Assoc 84(408):1024-1032

18. Hansen BB, Klopfer SO (2006) Optimal full matching and related designs via network flows. J Comput Graph Stat 15(3):609-627

19. Sekhon JS (2011) Multivariate and propensity score matching software with automated balance optimization: the matching package for R. J Stat Softw 42(7):1-52

20. Burnham KP, Anderson DR (eds) (2002) Model selection and multimodel inference: a practical information-theoretic approach, Second edn. Springer, New York

21. Anderson DR (2008) Model based inference in the life sciences: a primer on evidence. Springer, New York

22. Chambless LE, Diao G (2006) Estimation of time-dependent area under the ROC curve for long-term risk prediction. Stat Med 25(20):3474-3486

23. Chen SL, Bilchik AJ (2006) More extensive nodal dissection improves survival for stages I to III of colon cancer: a populationbased study. Ann Surg 244(4):602-610

24. Baxter NN, Virnig DJ, Rothenberger DA, Morris AM, Jessurun J, Virnig BA (2005) Lymph node evaluation in colorectal cancer patients: a population-based study. J Natl Cancer Inst 97(3):219-225

25. Maurer CA, Dietrich D, Schilling MK, Metzger U, Laffer U, Buchmann P, Lerf B, Villiger P, Melcher G, Klaiber C, Bilat C, Brauchli P, Terracciano L, Kessler K (2017) Prospective multicenter registration study of colorectal cancer: significant variations in radicality and oncosurgical quality-Swiss Group for Clinical
Cancer Research Protocol SAKK 40/00. Int J Colorectal Dis 32(1):57-74

26. VoyerTE Le, Sigurdson ER, Hanlon AL, Mayer RJ, Macdonald JS, Catalano PJ, Haller DG (2003) Colon cancer survival is associated with increasing number of lymph nodes analyzed: a secondary survey of intergroup trial INT-0089. J Clin Oncol 21(15):2912-2919

27. Babcock BD, Aljehani MA, Jabo B, Choi AH, Morgan JW, Selleck MJ, Luca F, Raskin E, Reeves ME, Garberoglio CA, Lum SS, Senthil M (2018) High-risk stage II colon cancer: not all risks are created equal. Ann Surg Oncol 25(7):1980-1985

28. Tsai HL, Huang CW, Chen CW, Yeh YS, Ma CJ, Wang JY (2016) Survival in resected stage II colorectal cancer is dependent on tumor depth, vascular invasion, postoperative CEA level, and the number of examined lymph nodes. World J Surg 40(4):1002-1009

29. Bockelman C, Engelmann BE, Kaprio T, Hansen TF, Glimelius B (2015) Risk of recurrence in patients with colon cancer stage II and III: a systematic review and meta-analysis of recent literature. Acta Oncol 54(1):5-16

30. Weixler B, Warschkow R, Güller U, Zettl A, von Holzen U, Schmied BM, Zuber M (2016) Isolated tumor cells in stage I \& II colon cancer patients are associated with significantly worse disease-free and overall survival. BMC Cancer 16:16-106. https://doi.org/10.1186/s12885-016-2130-7

31. Pagès F, Berger A, Camus M, Sanchez-Cabo F, Costes A, Molidor R, Mlecnik B, Kirilovsky A, Nilsson M, Damotte D, Meatchi T, Bruneval P, Cugnenc PH, Trajanoski Z, Fridman WH, Galon J (2005) Effector memory T cells, early metastasis, and survival in colorectal cancer. N Engl J Med 353(25):2654-2666

32. Gorog D, Nagy P, Peter A, Perner F (2003) Influence of obesity on lymph node recovery from rectal resection specimens. Pathol Oncol Res 9(3):180-183

33. Ostadi MA, Harnish JL, Stegienko S, Urbach DR (2007) Factors affecting the number of lymph nodes retrieved in colorectal cancer specimens. Surg Endosc 21(12):2142-2146

34. Wong SL (2009) Lymph node counts and survival rates after resection for colon and rectal cancer. Gastrointest Cancer Res 3(2 Suppl): S33-S35

35. Cahill RA, Lindsey I, Cunningham C (2010) Sentinel node mapping by colonic tattooing. Surg Endosc 24(9):2365-2366

36. Kang J, Park HS, Kim IK, Song Y, Baik SH, Sohn SK, Lee KY (2015) Effect of preoperative colonoscopic tattooing on lymph node harvest in T1 colorectal cancer. Int J Color Dis 30(10): $1349-1355$

37. Brown HG, Luckasevic TM, Medich DS, Celebrezze JP, Jones SM (2004) Efficacy of manual dissection of lymph nodes in colon cancer resections. Mod Pathol 17(4):402-406

38. Guller U, Zettl A, Worni M, Langer I, Cabalzar-Wondberg D, Viehl CT, Demartines N, Zuber M (2012) Molecular investigation of lymph nodes in colon cancer patients using one-step nucleic acid amplification (OSNA): a new road to better staging? Cancer 118(24):6039-6045

39. Wild JB, Iqbal N, Francombe J, Papettas T, Sanders DS, Ramcharan S (2017) Is it time for one-step nucleic acid amplification (OSNA) in colorectal cancer? A systematic review and metaanalysis. Tech Coloproctol 21(9):693-699

40. Croner RS, Geppert CI, Bader FG, Nitsche U, Späth C, Rosenberg R, Zettl A, Matias-Guiu X, Tarragona J, Güller U, Stürzl M, Zuber M (2014) Molecular staging of lymph node-negative colon carcinomas by one-step nucleic acid amplification (OSNA) results in upstaging of a quarter of patients in a prospective, European, multicentre study. Br J Cancer 110(10):2544-2550

41. Viehl CT, Guller U, Cecini R, Langer I, Ochsner A, Terracciano L, Riehle HM, Laffer U, Oertli D, Zuber M (2012) Sentinel lymph node procedure leads to upstaging of patients with resectable colon cancer: results of the Swiss prospective, multicenter study sentinel 
lymph node procedure in colon cancer. Ann Surg Oncol 19(6): 1959-1965

42. Weixler B, Rickenbacher A, Raptis DA, Viehl CT, Guller U, Rueff J, Zettl A, Zuber M (2017) Sentinel lymph node mapping with isosulfan blue or indocyanine green in colon cancer shows comparable results and identifies patients with decreased survival: a prospective single-center trial. World J Surg 41(9):2378-2386

43. Hohenberger W, Weber K, Matzel K, Papadopoulos T, Merkel S (2009) Standardized surgery for colonic cancer: complete mesocolic excision and central ligation-technical notes and outcome. Colorectal Dis 11(4):354-364

44. West NP, Hohenberger W, Weber K, Perrakis A, Finan PJ, Quirke P (2010) Complete mesocolic excision with central vascular ligation produces an oncologically superior specimen compared with standard surgery for carcinoma of the colon. J Clin Oncol 28(2): 272-278

45. Pelz JOW, Wagner J, Lichthardt S, Baur J, Kastner C, Matthes N, Germer CT, Wiegering A (2018) Laparoscopic right-sided colon resection for colon cancer-has the control group so far been chosen correctly? World J Surg Oncol 16(1):117

46. Bertelsen CA, Neuenschwander AU, Jansen JE, Wilhelmsen M, Kirkegaard-Klitbo A, Tenma JR, Bols B, Ingeholm P, Rasmussen LA, Jepsen LV, Iversen ER, Kristensen B, Gögenur I, Danish Colorectal Cancer Group (2015) Disease-free survival after complete mesocolic excision compared with conventional colon cancer surgery: a retrospective, population-based study. Lancet Oncol 16(2):161-168
47. Bertelsen CA, Neuenschwander AU, Jansen JE, Kirkegaard-Klitbo A, Tenma JR, Wilhelmsen M, Rasmussen LA, Jepsen LV, Kristensen B, Gögenur I, the Copenhagen Complete Mesocolic Excision Study (COMES), the Danish Colorectal Cancer Group (DCCG) (2016) Short-term outcomes after complete mesocolic excision compared with 'conventional' colonic cancer surgery. Br J Surg 103(5):581-589

48. Pox C, Aretz S, Bischoff SC, Graeven U, Hass M, Heußner P, Hohenberger W, Holstege A, Hübner J, Kolligs F, Kreis M, Lux P, Ockenga J, Porschen R, Post S, Rahner N, Reinacher-Schick A, Riemann JF, Sauer R, Sieg A, Scheppach W, Schmitt W, Schmoll HJ, Schulmann K, Tannapfel A, Schmiegel W; Leitlinienprogramm Onkologie der AWMF; Deutschen Krebsgesellschaft e. V; Deutschen Krebshilfe e. V.: S3-Leitlinie kolorektales Karzinom Version 1.0 - Juni 2013 AWMF Registernummer: 021/007OL. Z Gastroenterol 2013;51:753-854

49. Viehl CT, Ochsner A, von Holzen U, Cecini R, Langer I, Guller U, Laffer U, Oertli D, Zuber M (2010) Inadequate quality of surveillance after curative surgery for colon cancer. Ann Surg Oncol 17(10):2663-2669

50. Rueff J, Weixler B, Viehl CT, Ochsner A, Warschkow R, Gueller U, Mingrone W, Zuber M (2020) Improved quality of colon cancer surveillance after implementation of a personalized surveillance schedule. J Surg Oncol 122:529-537

Publisher's note Springer Nature remains neutral with regard to jurisdictional claims in published maps and institutional affiliations. 